\title{
O uso de um Ambiente Virtual de Aprendizagem como apoio às atividades presenciais no contexto do ensino médio
}

\author{
Claudete F. Oliveira ${ }^{1}$, Rommel W. Lima ${ }^{1}$ \\ ${ }^{1}$ Departamento de Informática - Universidade do Estado do Rio Grande do Norte \\ (UERN) \\ claudete_fo@yahoo.com,rommel.lima@gmail.com

\begin{abstract}
This article is in the area of technology applied to education and contemplates the use of a AVA, in the context of secondary education in the classroom, as a way to subsidize the teacher's pedagogic practice and expand the opportunities for education beyond the short and delimited space of physical presence of teachers and students in the same classroom. After the account of the experience, your results will be appointed on using Moodle in classroom discipline and the final considerations of this document.
\end{abstract}

Resumo. Este artigo situa-se na área das tecnologias aplicada à educação e contempla a utilização de um AVA, no contexto do ensino médio na modalidade presencial, como forma de subsidiar a prática pedagógica do professor e de ampliar as possibilidades de ensino para além do curto e delimitado espaço de presença física de professores e alunos na mesma sala de aula. Após o relato da experiência, serão apontados seus resultados acerca da utilização do Moodle em disciplina presencial e as considerações finais deste documento.

\section{Introdução}

As transformações tecnológicas que acontecem no mundo desempenham um papel relevante na sociedade, principalmente na educação, já que a escola constitui um processo permanente de construção de pontes entre o mundo escolar e o universo que nos cerca.

A inserção de tecnologias no contexto educacional é um desafio para a escola [Mercado 1998], pois essa aderência exerce uma função de um recurso voltado para uma ação pedagógica diferenciada, o que implica assumir mudanças nas ações educativas a partir de um trabalho coletivo de todos os profissionais da escola, destacando-se entre eles o professor. Para este, não basta a inserção de computadores na escola, é preciso integrar adaptações ao dia-a-dia, buscar novas formas de ensino-aprendizagem e trabalhar de uma forma a promover uma mudança cultural e uma visão produtiva desse conjunto de instrumentos [Mercado 1998].

As tecnologias estão presentes em todos os lugares, assim não se pode ignorar sua presença nem mesmo os desafios que se impõe tão pouco sua importância. Segundo [Perrenoud 2001] apud [Duso 2009 p. 61], a escola não pode ignorar o que ocorre no mundo, pois as novas tecnologias na educação e na comunicação transformam, consideravelmente, não só nossas maneiras de nos comunicar, mas de trabalhar, decidir e pensar. 
As facilidades proporcionadas pelas NTIC's (Novas Tecnologias da Informação e Comunicação), possibilitaram uma nova realidade educacional: o ensino mediado pelo computador e ainda a criação e aprimoramento das estratégias de ensino, apoiadas em Ambientes Virtuais de Aprendizagem (AVA).

Entende-se por Ambientes Virtuais de Aprendizagem, todos os ambientes computacionais com recursos das telecomunicações, que oferecem aos sujeitos um espaço de troca de informações, reflexões, estabelecimento de relações, pesquisa e elaboração de projetos [Moresco e Behar 2005].

Moresco e Behar (2005) acrescentam ainda que trata-se de uma estrutura composta de funcionalidades, interface e proposta pedagógica, enriquecida por imagens, sons, movimentos e dispositivos de comunicação síncrona e/ou assíncrona.

Os AVA agregam várias tecnologias encontradas na Internet para provê a comunicação, disponibilização de materiais e administração de cursos. O conjunto de funcionalidades que cada ambiente possui é estabelecido pelas ferramentas disponibilizadas em cada ambiente. Segundo Moresco e Behar (2003) as ferramentas de comunicação disponibilizadas pelos AVA permitem dinamizar a comunicação e, consequentemente, a resolução de problemas, como pode ser observado nos chats, listas de discussões e fóruns, além dos correios eletrônicos. Os AVA possuem ainda diferentes posturas pedagógicas.

As atividades organizadas no AVA propiciam a flexibilidade de horários, de local e de ritmo de aprendizado, podendo contribuir para a percepção de que o conhecimento está disponível e não depende do lugar e do momento [Duso 2009]. Dessa forma, estes ambientes oferecem aos alunos a oportunidade de definirem seus próprios caminhos de acesso às informações desejadas, afastando-se de modelos tradicionais de ensino e garantindo aprendizagens personalizadas.

Entretanto, para se chegar até o curso que será disponibilizado para os alunos, pressupõem-se uma série de atividades que vão desde a preparação e elaboração de materiais, até a execução e acompanhamento do curso. Dessa forma, é primordial que professor esteja capacitado para utilização de um AVA, a fim de aproveitar todo o potencial que estes ambientes possuem utilizando-os de forma eficaz, criando novas metodologias e estratégias de ensino que superem a reprodução do conhecimento e levem a produção de conhecimento.

Nesse contexto define-se o objetivo desse trabalho que é investigar as contribuições do uso do AVA Moodle como suporte ao ensino presencial, para auxiliar o professor em sua prática pedagógica e proporcionar ao aluno maiores condições de construção e apropriação do conhecimento.

Para isto, este artigo apresenta fatores que motivaram a escolha do Moodle para ser utilizado no trabalho; em seguida é apresentado relato da experiência em turma do $3^{\circ}$ ano do ensino médio da rede pública de ensino e uma análise dos resultados obtidos.

\section{O AVA Moodle}

Moodle (Modular Object-Oriented Dynamic Learning Environment) [Moodle 2009] Ambiente de Aprendizagem Dinâmico Modular Orientado a Objeto, é um software desenvolvido para ajudar os educadores a criar cursos on-line [Sabbatini 2007]. É um ambiente para criação, participação e administração de cursos na web. 
Quando se decide pela utilização de um AVA é preciso estabelecer critérios coerentes que sejam mais adequados ao processo educacional. Aspectos como funcionalidades (segurança de aceso, registro sob a licença GPL - Gnu Public License [GNU 2007]), adequação (viabiliza o aprendizado de forma eficaz e prazerosa), etc.), usabilidade (facilidade de utilização, navegação rápida, interface agradável, facilidade de envio de tarefas, etc) e ferramentas integrantes são fatores que contribuem na decisão podendo assim, possibilitar e promover situações de aprendizagem que mobilizem os alunos a gerar significados e, por conseguinte, melhorar a construção de conhecimentos de forma autônoma.

Desta forma, o AVA utilizado como apoio ao ensino presencial foi o Moodle. Ao pensar em se trabalhar com o este AVA se justifica por algumas vantagens descritas abaixo:

- Grande possibilidade de suas ferramentas que se assemelham as da Internet.

- É um software livre que tem sido utilizado por diversas instituições não somente pelo fato de ser gratuito, mas pela sua funcionalidade.

- O download pode ser realizado gratuitamente através do Portal Moodle.

- Permite realização de tarefas, construções coletivas e avaliações.

- Encontra-se traduzido em mais de 70 idiomas.

Outro destaque para o Moodle é que seu criador, Martin Dougiamas, adotou a filosofia educacional do Construtivismo Social no seu desenvolvimento. Assim, essa postura valoriza as discussões em grupo, a construção colaborativa do conhecimento e reflexão crítica, onde o professor/tutor atua como mediador do processo [Machado Junior 2008, p. 76].

Além de todas essas características outro fator que motivou a escolha desse ambiente é que ele é utilizado por instituições renomadas como a Universidade Federal do Rio Grande do Norte - UFRN, o Instituto Federal do Rio Grande do Norte - IFRN e a Universidade do Estado do Rio Grande do Norte - UERN.

\section{O Processo de Avaliação}

O processo de avaliação é um dos elementos centrais e uma prática indispensável ao processo de escolarização e da prática pedagógica. Por essa razão a avaliação é uma preocupação do docente e continua sendo um tema polêmico no contexto educacional, o que se expressa pelas inúmeras publicações na área. Segundo Esteban (2010):

\footnotetext{
[...] muitas são as polêmicas relativas à avaliação, envolvendo seus fundamentos teórico-epistemológicos, suas funções e modalidades no processo ensino-aprendizagem e relações com a produção dos resultados escolares, sua conformação na prática, que abre para a reflexão e para o debate sobre o próprio objeto da avaliação, sobre os sujeitos que dela participam, os modos desta participação, os instrumentos e procedimentos usados, seus tempos e espaços de realização, os valores que a orientam, a articulação de suas dimensões qualitativa e quantitativa. [Esteban 2010, p.06].
}

Vale então a ressalva de que tal temática por ser demais complexa não há aqui a intenção de discuti-la em um breve texto, mas sim ressaltar a importância e a necessidade da avaliação. 
Tanto na EaD como no ensino presencial, existem três modalidades de avaliação amplamente conhecidas - somativa, diagnóstica e formativa-, cada uma delas com uma função específica. De acordo com Litto e Formiga (2009) a avaliação somativa tem o propósito de classificar o aluno, atribuindo-lhe uma nota; a diagnóstica não é mensurável em termos de nota, mas é importante para conhecer o grau de educabilidade cognitiva do aluno. A formativa, por sua vez, possui várias classificações, utiliza diversos instrumentos e busca o aperfeiçoamento do processo de ensino e aprendizagem, sendo uma avaliação mais significativa para a EaD. Para Rodrigues (1998), na avaliação formativa se procura o aprendizado do aluno, ajudando-o em sua trajetória em busca do conhecimento. Propicia também feedback ao aluno e professor com a função de controle qualitativo do processo de ensino-aprendizagem. O acompanhamento é feito por meio das atividades disponibilizadas no AVA, selecionadas pelo professor para tal objetivo.

Para verificar se os alunos estão atingindo os objetivos previstos, isto é, quais os resultados alcançados durante o desenvolvimento das atividades por meio da mediação professor, aluno e conhecimento, destacamos ainda a Taxonomia dos objetivos educacionais, também popularizada como taxonomia de Bloom.

A Taxonomia de Bloom possui uma estrutura hierárquica que vai do mais simples ao mais elaborado, proporcionando o desenvolvimento de atividades que vão crescendo em complexidade até atingir os níveis mais altos [Bloom 1977]. A idéia central da taxonomia é a de que aquilo que os educadores querem que os alunos saibam (objetivos educacionais) pode ser arranjado numa hierarquia do menos para o mais complexo.

A classificação proposta por Bloom dividiu as possibilidades de aprendizagem em três domínios educativos: o cognitivo, o afetivo e o psicomotor. O domínio cognitivo é o modelo mais empregado para se responder ao "como avaliar". Geralmente quando é citada a Taxonomia de Bloom, refere-se a taxonomia utilizada no domínio cognitivo [Bloom 1977].

O nível Cognitivo, foco deste trabalho, relaciona-se com o aprender, dominar um conhecimento. Envolve a aquisição de um novo conhecimento, do desenvolvimento intelectual, de habilidade e de atitudes. Nesse domínio, os objetivos foram agrupados em seis categorias (níveis) e são apresentadas numa hierarquia de complexidade e dependência, da mais simples a mais complexa.

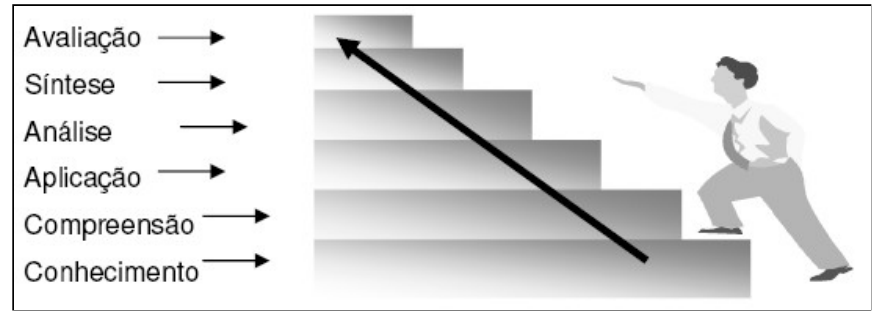

Figura 1. Níveis do domínio cognitivo

Para ascender a uma nova categoria, é preciso ter obtido um desempenho adequado na anterior, pois cada uma utiliza capacidades adquiridas nos níveis anteriores. As categorias desse domínio são: Conhecimento, Compreensão, Aplicação, Análise, Síntese e Avaliação como expressa a figura 1.

Relacionados às categorias, estão às declarações de desempenho e os verbos usados em cada nível como pode ser visto em Lima (2008). 
O nível afetivo fundamenta-se em sentimentos e posturas. Envolve categorias ligadas ao desenvolvimento da área emocional e afetiva, que incluem comportamento, atitude, responsabilidade, respeito, emoção e valores.

O nível psicomotor está ligado a habilidades físicas específicas. Bloom e sua equipe não chegaram a definir uma taxonomia para a área psicomotora, mas outros o fizeram e chegaram a seis categorias que incluem idéias ligadas a reflexos, percepção, habilidades físicas, movimentos aperfeiçoados e comunicação não verbal.

\section{Metodologia aplicada ao trabalho}

A metodologia desenvolvida combina o ensino a distância e ensino presencial, de forma a aproveitar as facilidades e flexibilidade das tecnologias de $\mathrm{EaD}$, e ao mesmo tempo preservando os benefícios dos contatos pessoais.

As atividades foram desenvolvidas com alunos do $3^{\circ}$ ano do Ensino Médio da Escola Estadual Raimundo Soares em Natal/RN, durante o ano letivo de 2011. O critério de seleção dos alunos participantes foram estar trabalhando e/ou fazendo cursinho preparatório para vestibular, pois os alunos com esses pré-requisitos costumam ter um maior índices de faltas as aulas ou ter dificuldades em acompanhar, com êxito, os conteúdos ministrados devido a grande quantidade de tarefas a cumprir.

No primeiro momento houve a explanação, em sala de aula, do trabalho a ser realizado. Na oportunidade falamos sobre $\mathrm{EaD}$, de um modo geral, sobre os potenciais pedagógicos das ferramentas oferecidas no Moodle e sobre a importância de experimentar esta tecnologia como mecanismo de apoio ao ensino presencial e também sobre a forma como seriam avaliados.

O curso intitulava-se "Matemática Básica", sua organização foi dividida em bimestres, de acordo com os bimestres escolares, e em cada um foi disponibilizada as atividades referentes ao conteúdo e o material de apoio. Como as aulas ocorreram presencialmente, foi disponibilizado programação do curso, resumo dos capítulos e arquivos com vídeo aulas para livre acesso pelos alunos. Com isso, alunos que eventualmente perderam uma aula puderam acessar os vídeos desta aula perdida antes da próxima aula com o intuito de não ter seu desempenho na disciplina prejudicado.

Durante a etapa de planejamento, procurou-se definir os objetivos pedagógicos das atividades e os critérios a serem considerados na avaliação destas. Para atender essa necessidade foram utilizadas as ferramentas Mapa de Conteúdos (MC) e Mapa de Dependências (MD). O MC é uma ferramenta, baseada nos Mapas Conceituais, que possibilita apresentar a disciplina ou curso através de uma visualização gráfica dos conteúdos e das relações existentes entre os mesmos [Lima 2011]. O MD é uma ferramenta composta por um conjunto de objetivos educacionais relacionados entre si, através da hierarquia definida pela Taxionomia de Bloom, que são apresentados de forma gráfica [Lima 2011].

Dessa forma o MC foi utilizado como instrumento didático, onde os alunos poderiam visualizar a distribuição de conteúdos e a representação mais completa das relações entre eles. Por não ser auto-instrutivo, pois muitas vezes o planejamento é convertido para uma forma de compreensão de quem o faz e também adequado aos seus conhecimentos, a explicação do $\mathrm{MC}$ foi feita em sala de aula para que se tornasse potencialmente significativo. A ferramenta MD foi utilizada para planejar o curso através 
de objetivos educacionais. Para cada conteúdo especificado no MC foi definido o objetivo educacional e o comportamento necessário para atingí-lo.

A avaliação do aluno aconteceu de duas formas diferentes: de forma quantitativa, que é a mais tradicional, através da atribuição de uma nota as atividades desenvolvidas pelo aluno. Nesse caso foi definida a nota mais alta da atividade. E de forma qualitativa através de atividades desenvolvidas de acordo com o Mapa de Dependência; dos questionários de avaliação de cursos - específicos para AVA - e do repasse de informações ao aluno pela utilização do campo de feedback.

Entende-se por feedback um parecer, um retorno do professor para o aluno em relação a(s) sua(s) resolução(ões), com o objetivo de avaliar. Esse acompanhamento propicia a retroalimentação, fator indispensável em educação a distância. Dentro deste contexto, alunos poderão retomar o caminho proposto para atingir o objetivo de melhorar o seu desempenho, reabilitar-se e por fim adquirir conhecimento.

As avaliações formativas foram compostas por 06 (seis) questões, referentes ao conteúdo em estudo, onde cada uma estaria associada a uma categoria da taxonomia de Bloom com o respectivo objetivo educacional especificado.

Os questionários de avaliação de cursos, específicos para AVA referem-se a três tipos de formulários de pesquisa conhecidos como ATTLS (Attitude Towards Thinking and Learning Survey), COLLES (Constructivist On-Line Learning Environment Survey) e Incidentes críticos. Nestes questionários não há respostas certas ou erradas, o interesse é apenas na opinião do aluno e não têm nenhum impacto sobre a avaliação do participante. Este tipo de atividade favorece a reflexão sobre os processos de aprendizagem durante o curso [Moodle 2009].

O ATTLS é um instrumento de inspeção que fornece gráficos e mapas fáceis de ler. Ajuda a medir até que ponto uma pessoa tem o saber "conectado" (SC) ou um saber "destacado"(SD). Pessoas com valores SC maiores tendem a ver os processos de aprendizagem como experiências prazerosas, cooperam com maior freqüência, procuram ser agradáveis e demonstram interesse em construir a partir da idéia dos outros, enquanto as pessoas com valores SD mais altos tendem a ter uma posição mais crítica e criar polêmicas [Moodle 2009]. Esses dois estilos de aprendizagem tem o objetivo de fazer uma pesquisa sobre as posturas dos participantes do curso perante a aprendizagem e a reflexão crítica, e não das capacidades de aprender ou do poder intelectual.

O instrumento COLLES foi projetado para auxiliar professores, de uma perspectiva construtivista social, a acessar qualidade de seu ambiente de aprendizagem on line obtendo medidas de percepções e preferências dos estudantes [Taylor 2000 apud Moodle 2009, p.19]. O questionário COLLES é formado por 24 declarações distribuídas em 6 grupos, cada um deles relativo a um ponto importante de avaliação da qualidade do processo de aprendizagem no ambiente virtual. São eles: relevância, reflexão crítica, interatividade, apoio dos tutores, apoio dos colegas e compreensão. Há três tipos de questionários COLLES: Expectativas, Expectativas/experiência efetiva e Experiência efetiva.

A avaliação Incidentes críticos deve ser respondida com comentários dos alunos sobre tópicos como o envolvimento, enquanto participante do curso; sobre as ações de outros participantes nos fóruns e eventos mais surpreendentes.

Dentre esses questionários foram aplicados a avaliação COLLES - Experiência Efetiva - e Incidentes críticos os quais são apropriados para final de cursos. A avaliação experiência efetiva mostra a relação entre as expectativas dos participantes e sua 
experiência efetiva. $\mathrm{O}$ objetivo é fazer uma pesquisa sobre a medida em que as atividades do curso favorecem o seu processo de aprendizagem.

As atividades utilizadas na implementação da metodologia foram Tarefa, Questionário e Fórum. Através da atividade Tarefa os alunos submeteram arquivos para avaliação da resolução da tarefa para a qual foi atribuída uma nota e adicionado um feedback para o aluno.

A atividade Questionário foi a mais utilizada durante o processo, pois é a que mais se assemelha aos tradicionais trabalhos passados em sala de aulas presenciais. Foram utilizadas questões do tipo múltipla escolha, verdadeiro-falso e discursivas para as quais a correção era acompanhada de um feedback, além da nota. Foi proposto questionários sistematizados de acordo com Taxonomia de Bloom, compostos de seis perguntas onde cada uma representa um nível da hierarquia.

O Fórum foi utilizado com o propósito de estabelecer conversação entre os alunos, permitindo assim, trocar experiências, discutir a cerca dos temas propostos ou estudados em sala de aula. Para esta atividade, a princípio, não seria atribuída uma nota e sim um feedback possibilitando a comunicação e interação professor-aluno. Porém para estimular a participação também foi adicionada uma pontuação extra.

As atividades eram parte integrante a composição da nota bimestral, substituindo os trabalhos e testes presenciais, ficando o aluno na obrigatoriedade de fazer presencialmente a prova escrita de caráter classificatório.

Durante o desenvolvimento do curso as teorias eram ministradas em sala de aula, assim como os esclarecimentos e dúvidas das atividades, onde os alunos relatavam experiências com o uso da tecnologia. Apesar de sempre instigá-los ao uso de e-mails para tal situação, os mesmos preferiam o contato pessoal.

\section{Análise e Resultados}

\subsection{Análise das ferramentas do Moodle}

As ferramentas utilizadas tiveram uma boa aceitação por parte dos alunos e estes não demonstraram dificuldades em utilizá-las.

O MC e o MD, por serem ferramentas gráficas, forneceram uma forma agradável de visualização do processo, facilitando a assimilação, reflexão e contribuindo dessa forma com o processo de aprendizagem, pois nossa mente opera muito mais facilmente com imagens organizadas. O processo de ensino pôde ser fortalecido através da estruturação da disciplina, proporcionada pelo MC, cuja visualização das relações entre conteúdos possibilitou uma melhor definição dos objetivos educacionais necessários para se trabalhar cada conceito. O MD, por sua vez, possibilitou mostrar quais comportamentos o aluno deveria apresentar para alcançar o objetivo proposto.

O desempenho dos alunos, na análise de dados qualitativos, nas questões referentes a cada nível do processo cognitivo da taxonomia de Bloom identificou-se que os mesmos tiveram dificuldades em atender aos objetivos propostos. No intuito de sanar essa lacuna, foi enviado feedback referente a cada pergunta além de discussão e esclarecimentos promovidos em sala de aula. A discussão das dificuldades em resolver esses testes foi utilizada para tornar os alunos conscientes do tipo de conhecimento que eles têm no momento e as possibilidades de aprofundamento desses conhecimentos.

Também, para efeito de análise qualitativa, pôde-se observar através dos relatórios gerados referentes ao questionário Colles (Experiência Efetiva) que os 
objetivos desejados atingiram um estágio intermediário. Essa informação é importante para que o professor a utilize como eixo norteador, percebendo o que ainda pode ser melhorado, elaborando-se novas estratégias para que se efetue a produção do conhecimento.

Para a avaliação incidentes críticos o Moodle não gera relatórios pelo fato das respostas serem pessoais. As mesmas ajudam aos professores na melhoria, no aperfeiçoamento das atividades propostas nos cursos.

\subsection{Análise dos resultados da turma}

A participação dos alunos foi bastante contundente, apesar de nem todos os alunos terem participado de todas as atividades. Algumas atividades tiveram que ser prorrogadas para que fosse conseguida a contribuição da maioria dos participantes.

É relevante mencionar, que por algumas vezes, as dificuldades no cumprimento das tarefas solicitadas estavam relacionadas a dificuldade de conseguir acesso ao ambiente ou manter-se conectado.

Cabe ressaltar que dos $100 \%$ dos alunos cadastrados no ambiente houve a evasão de $12 \%$, que nem chegaram a iniciar as atividades, e $6 \%$ que foi adicionado ao grupo através de seu pedido para participação. Dessa forma $88 \%$ participaram efetivamente.

Para fazer uma avaliação da evolução dos alunos participantes do curso, foi feita uma comparação dos resultados obtidos durante o ano de 2011 que serão apresentados através da figura 02. Esta comparação tem como objetivo sinalizar ao professor resultados estatísticos que podem indicar a evolução da turma por meio do AVA no ensino presencial.

Dos $100 \%$ dos alunos inscritos no curso, 33,3\% foram aprovados, $60 \%$ ficaram em recuperação e $6,6 \%$ foram retidos. Dos $100 \%$ dos alunos que não participaram do curso 7,6\% foram aprovados, 84,6\% ficaram em recuperação e 7,6\% foram retidos.

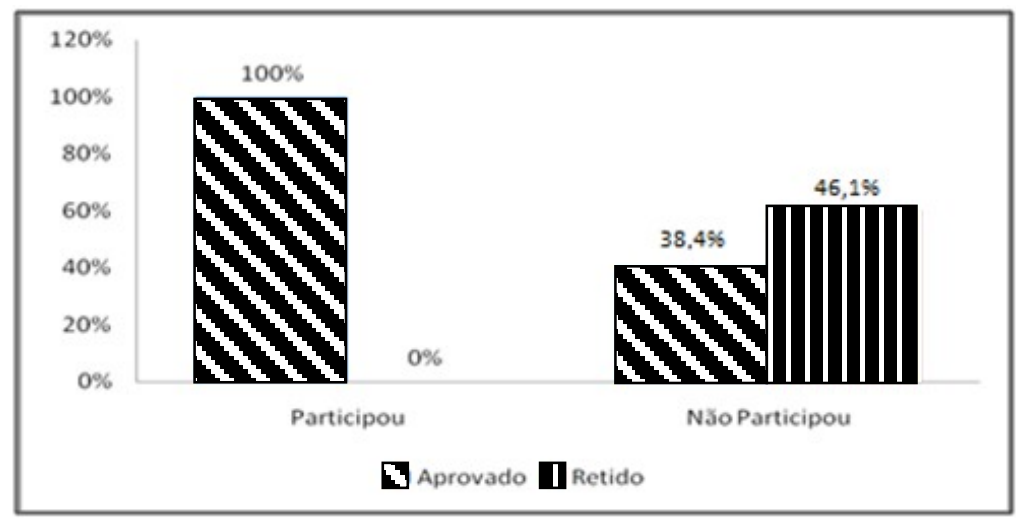

Figura 2. Gráfico com resultado final

Após a aplicação das provas finais o novo resultado se deu da seguinte forma: dos $60 \%$ dos alunos, participantes do curso, que ficaram em recuperação todos foram aprovados, representando $100 \%$ de aprovação. Enquanto que dos 84,6\% dos alunos, que não participaram do curso e ficaram em recuperação, 38,4\% foram aprovados e $46,1 \%$ ficaram retidos, como mostra a figura 2. 


\section{Conclusão}

A essência deste trabalho é a utilização do AVA como apoio ao ensino presencial. Podemos constatar um efeito positivo. A introdução do AVA na disciplina aconteceu durante todo o ano letivo, apesar de uma longa interrupção devido a greve de professores, proporcionando melhores resultados da aprendizagem para os participantes do processo em comparação ao grupo que não participou, conforme gráfico 01 , e também possibilitou conhecer os seguintes efeitos:

- A cooperação foi amplamente construída ao longo do curso. Nem sempre obtida no início das atividades, mas com um grande saldo positivo ao longo do curso.

- A verificação de indícios na autonomia dos alunos, não só pelo fato da constatação dos acessos ao ambiente em horários variados, mas também nas indicações positivas feitas pelos alunos, em sala de aula, com relação à metodologia cooperativa. Isto é um indicativo de que o conceito de aprendizagem cooperativa vivida na disciplina de matemática foi bem assimilado.

- A estrutura do ambiente colaborou para o surgimento de interações novas em relação àquelas do contexto presencial, mostrando a importância do ambiente na construção de uma postura cooperativa.

- Ampliação do campo de atuação do professor apresentando nova oportunidade de ensino.

Em relação aos aspectos computacionais, os alunos tiveram a possibilidade de conhecer como são utilizados os ambientes virtuais de ensino, sua estrutura e funcionamento.

O questionário sistematizado de acordo com a Taxonomia de Bloom, além de proporcionar uma motivação para o aprendizado, forneceu subsídio para aluno avançar em graus de complexidade de conhecimento e permitir ao professor observar como e de que modo ele evoluiu. Oportunizando, ainda, expandir nossas capacidades e fazer algo melhor do que fizemos.

Espera-se que os alunos participantes desse processo vejam nesta proposta uma oportunidade de aprendizagem, através das ferramentas oferecidas de forma on-line e avaliações presenciais. E que os resultados deste trabalho seja útil para outros professores que pretendem usar, ou que já estejam utilizando AVA em situações semelhantes.

Diante das afirmativas, compreende-se que o objetivo do estudo foi alcançado, e espera-se com este impulsionar o desenvolvimento de novas pesquisas, visto que este não pretende esgotar a temática, mas sim, deixar posicionamentos que envolvam o aprimoramento de novas perspectivas teóricas, que poderão nortear questionamentos futuros.

\section{Referências}

Bloom, B. S. et al. (1977) Taxonomia de objetivos educacionais: domínio cognitivo. Trad. Flávia Maria Sant'anna. 6. Ed. Globo: Porto Alegre - RS.

Duso, L. (2009) Uso de Ambiente Virtual de Aprendizagem de Temas Transversais no ensino de Ciências. Revista Brasileira de Ensino de Ciência e Tecnologia, R.B.E.C.T, v. 2, n. 3, set/dez. 
Esteban, M. T. (2010) Avaliação: um tema polêmico - Proposta da série. Revista Salto para o Futuro, Ano XX Boletim 18 - Novembro.

Filho, A. R. P. (2009) Moodle: um sistema de gerenciamento de cursos (versão 1.5.2+). Brasília: Departamento de Engenharia Civil e Ambiental. Universidade de Brasília. http://www.abed.org.br/congresso2007/tc/4162007104526AM.pdf, Outubro.

GPL. (2007) http://www.gnu.org/copyleft/gpl.html, Junho.

Lima, R.W. e Fialho, S. V. (2008) Mapa de Dependências: Uma ferramenta para aplicação da Taxonomia de Bloom na Educação a Distância. In: XIX Simpósio Brasileiro de Informática na Educação, 2008, Fortaleza. XIX Simpósio Brasileiro de Informática na Educação, 2008.

Lima, R.W. e Fialho, S. V. (2011) Mapa de Conteúdos e Mapa de Dependências: ferramentas para um planejamento com base em objetivos educacionais. Revista de Exatas e Tecnológica - RETEC. v. 2, p. 10, 2011.

Litto, F. M. e Formiga, M. (2009) Educação a distância: o estado da arte. São Paulo: Pearson Education do Brasil.

Machado Júnior, F. S. (2008) Interatividade: e interface em um ambiente virtual de aprendizagem. Passo Fundo: IMED.

Mercado, L. P. L. M. (1998) Formação docente e novas tecnologias. IV Congresso Iberoamericano de Informática na Educação, realizado em Brasília - DF, no período de 20 a 23 de outubro, 1998.

Moresco, S. F. S. e Behar, P. A. (2005) Rooda tekton: Um objeto pedagógico para aprendizagem de física. IV Encontro Ibero-americano de coletivos escolares e redes de professores que fazem investigação na sua escola, Lajeado-RS.

Moresco, S. F. S. e Behar, P. A. (2003) Rooda Tekton: uma proposta pedagógica no ambiente virtual de aprendizagem Rooda. XIV Simpósio Brasileiro de Informática na Educação, Rio de Janeiro-RJ.

Perrenoud, P. (2001) Agindo na urgência, atuando na incerteza. Porto Alegre: Artmed.

Rodrigues, R. S.(1998) Modelo de avaliação para cursos no ensino à distância: estrutura, aplicação e avaliação. Florianópolis: UFSC (Dissertação de Mestrado em Engenharia de Produção - Programa de Pós-Graduação em Engenharia de Produção UFSC).

Taylor, P. C. (2009) Moodle: usando comunidades de aprendizes para criar um sistema de fonte aberta de gerenciamento de curso. In: Alves, Lynn; Barros, Daniela; Okada, Alexandra. (Org) Moodle: estratégia pedagógica e estudo de caso. Salvador: EDUNEB.

Sabbatini, R. M. E. (2007) Ambiente de Ensino e Aprendizagem via Internet: a Plataforma Moodle. São Paulo: Instituto EduMed. 